\title{
Role of the Major Glutamate Transporter GLT1 in Nucleus Accumbens Core Versus Shell in Cue-Induced Cocaine- Seeking Behavior
}

\author{
Kathryn D. Fischer, Alexander C.W. Houston, and George V. Rebec \\ Program in Neuroscience, Department of Psychological and Brain Sciences, Indiana University, Bloomington, Indiana 47405
}

Relapse to cocaine-seeking behavior requires an increase in nucleus accumbens (NAc) core glutamate transmission. Decreased expression of glutamate type I transporter (GLT1), which is responsible for $>90 \%$ of glutamate clearance, occurs in the core of rats withdrawn from cocaine self-administration, while treatment with ceftriaxone, a $\beta$-lactam antibiotic previously shown to increase GLT1 expression and function in rodents, upregulates GLT1 and attenuates cue-induced cocaine reinstatement. Here, we tested the effects of increasing GLT1 expression on cue-induced cocaine seeking in rats exposed to either limited $(2 \mathrm{~h} / \mathrm{d})$ or extended $(6 \mathrm{~h} / \mathrm{d})$ cocaine access followed by short $(2 \mathrm{~d})$ or long $(45 \mathrm{~d})$ withdrawal periods. Treatment with ceftriaxone $(200 \mathrm{mg} / \mathrm{kg}$, i.p.) upregulated core GLT1 expression and attenuated cue-induced cocaine-seeking behavior only in rats exposed to long withdrawal periods, with a greater effect in the extended-access condition. Pearson's correlation revealed GLT1 expression in core to be inversely correlated with cue-induced cocaine-seeking behavior. To localize the effects of GLT1 upregulation within NAc, we tested the hypothesis that blockade of GLT1 in NAc core, but not shell, would reverse the ceftriaxone-mediated effect. Rats withdrawn from cocaine self-administration were treated with the same dose of ceftriaxone followed by intracore or intrashell infusions of one of two GLT1 blockers, dihydrokainic acid (500 $\mu \mathrm{M})$ or DL-threo- $\beta$-benzyloxyaspartate (250 $\mu \mathrm{M})$, or saline. Our results reveal that the ceftriaxone-mediated attenuation of cue-induced cocaine reinstatement is reversed by GLT1 blockade in core, but not shell, and further implicate core GLT1 as a potential therapeutic target for cocaine relapse.

\section{Introduction}

A critical aspect of addiction is the return to drug use after periods of abstinence. Ample evidence implicates the nucleus accumbens (NAc) and its glutamatergic input from prefrontal cortex (PFC) in cocaine relapse (Weiss et al., 2000; McFarland et al., 2003; Kalivas et al., 2009; Lüscher and Malenka, 2011). The NAc comprises two subregions, core and shell, which have differential functionality in drug seeking (McFarland and Kalivas, 2001; Everitt and Robbins, 2005). In core, basal glutamate levels are decreased following cocaine self-administration but increased during cocaine reinstatement (McFarland et al., 2003). Inhibition of the PFC (prelimbic) projection to core attenuates both reinstatement and the rise in extracellular glutamate (McFarland

Received July 10, 2012; revised April 17, 2013; accepted April 18, 2013.

Author contributions: K.D.F., A.C.W.H., and G.V.R. designed research; K.D.F. and A.C.W.H. performed research; K.D.F., A.C.W.H., and G.V.R. analyzed data; K.D.F., A.C.W.H., and G.V.R. wrote the paper.

This work was supported, in part, by the National Institute on Drug Abuse (NIDA) (R01 DA 02451, P50 DA 05312 R01 DA 12964) and by the METACyt Initiative of Indiana University, which was funded, in part, through a major grant from the Lilly Endowment. We thank Faye Caylor for administrative assistance and Paul Langley for technical support. We also acknowledge NIDA (Chemistry and Physiological Systems Research Branch) for the contribution of cocaine hydrochloride.

The authors declare no competing financial interests.

Correspondence should be addressed to George V. Rebec, 1101 E. $10^{\text {th }}$ St, Bloomington, IN 47405-7007. E-mail: rebec@indiana.edu.

K.D. Fischer's present address: Department of Neurology and the F.M. Kirby Neurobiology Center, Children's Hospital Boston, Boston, MA 02115.

A.C.W. Houston's present address: Molecular and Cellular Neuroscience Program, Department of Brain and Cognitive Sciences, Massachusetts Institute of Technology, Cambridge, MA 02139.

DOI:10.1523/JNEUROSCI.3278-12.2013

Copyright $\odot 2013$ the authors $\quad 0270-6474 / 13 / 339319-09 \$ 15.00 / 0$ et al., 2003), whereas reinstatement is unaffected by inactivation of the PFC (infralimbic)-shell projection (Capriles et al., 2003). The increase in core glutamate can be explained by downregulation of glutamate type 1 transporter (GLT1) (Knackstedt et al., 2010), the transporter responsible for removing $>90 \%$ of extracellular glutamate (Danbolt, 2001; Rothstein et al., 2005). Interestingly, treatment with ceftriaxone, a $\beta$-lactam antibiotic, upregulates core GLT1 expression in rats trained to selfadminister cocaine and prevents cue-induced and cocaineinduced reinstatement (Sari et al., 2009; Knackstedt et al., 2010).

Most of these self-administration reports used extinction/ reinstatement models in animals exposed to limited-access conditions $(\sim 2 \mathrm{~h} / \mathrm{d})$. However, increasing access to drug selfadministration and introducing long withdrawal periods induce behavioral and morphological changes that more adequately capture key features of human addiction (Ahmed and Koob, 1998; Ferrario et al., 2005; Ahmed, 2012). In fact, extending drug access to $>6 \mathrm{~h} / \mathrm{d}$ elicits behaviors that closely resemble compulsive drug seeking. Moreover, introducing withdrawal periods following self-administration results in a time-dependent increase in drug relapse, known as incubation of cocaine craving (Grimm et al., 2001; Lu et al., 2004; Zavala et al., 2007; Conrad et al., 2008). This effect directly relates to changes in NAc AMPA receptors that lack GluR2 (Conrad et al., 2008), implicating NAc glutamate in relapse following abstinence (but see also See et al., 2007). We found that increasing access during cocaine self-administration results in a greater core and shell GLT1 downregulation and that introducing long withdrawal periods results in a greater core 
GLT1 downregulation (Fischer-Smith et al., 2012). Although upregulation of GLT1 following ceftriaxone treatment has been shown to block cue-induced cocaine reinstatement in rats, ceftriaxone has not been tested in cocaine-seeking rats following withdrawal, nor is it clear whether core and shell GLT1 are differentially involved in this effect. Here, we tested the hypothesis that ceftriaxone treatment would upregulate core GLT1 expression and attenuate cue-induced cocaine seeking in longwithdrawal $(45 \mathrm{~d})$ rats exposed to either limited or extended cocaine access. These effects of ceftriaxone should not occur in rats exposed to a brief withdrawal ( $2 \mathrm{~d}$ ) because testing follows shortly after cocaine self-administration and because ceftriaxone fails to alter the maintenance of cocaine self-administration (Sondheimer and Knackstedt, 2011). To localize the effect of ceftriaxone within NAc, we tested the hypothesis that GLT1 blockade in core, but not shell, would reverse the ceftriaxonemediated attenuation of cue-induced cocaine-seeking behavior.

\section{Materials and Methods}

Subjects. Data were obtained from 218 male, Sprague Dawley rats (300$350 \mathrm{~g}$ at the start of experimentation) bred from animals supplied by Harlan Industries. Rats were assigned to a Western blot experiment (Experiment 1) or to a brain infusion experiment (Experiment 2). Rats were single-housed in a temperature and humidity controlled vivarium. Food and water were available ad libitum, and lights operated on a $12 \mathrm{~h}$ cycle (on at 7:00 A.M.). All housing and experimental procedures were approved by the Institutional Animal Care and Use Committee.

Behavioral chambers. Rats were tested in eight standard operant chambers [ $27 \mathrm{~cm}$ (length) $\times 22.5 \mathrm{~cm}$ (width) $\times 23.5 \mathrm{~cm}$ (height) ] supplied by MED Associates. One wall of each chamber was equipped with two levers (active and inactive; spaced $13 \mathrm{~cm}$ apart and $10 \mathrm{~cm}$ above the grid floor) and a $1 \mathrm{~W}$ cue light (located $3.5 \mathrm{~cm}$ above each lever). The number of inactive lever presses was $<5 \%$ of that of active lever presses throughout the entire study. A food hopper, located between the two levers, was connected to a food dispenser installed outside each chamber. A programmable speaker, used to deliver a tone $(54 \mathrm{~dB})$, was installed on the opposite wall along with a $5 \mathrm{~W}$ house light. Each chamber was housed in a light-attenuating and sound-attenuating cubicle. A fluid pump, positioned outside each cubicle, was used to deliver cocaine. A separate infusion pump, positioned outside each cubicle, was used to deliver intracerebral infusions of dihydrokainic acid (DHK), DL-threo- $\beta$ benzyloxyaspartate (DL-TBOA), or saline vehicle for Experiment 2 rats.

Animal surgery. All rats from Experiments 1 and 2 were anesthetized with xylazine (10 mg/kg, i.p.) and ketamine $(80 \mathrm{mg} / \mathrm{kg}$, i.p.) for surgical implantation of a jugular vein catheter as previously described (Sun and Rebec, 2003). Rats from Experiment 2 were subsequently positioned in a stereotaxic frame for bilateral brain cannula implantation. The skull was exposed and holes drilled over the target sites. For intra-NAc core infusions, bilateral guide cannulas were implanted $0.60 \mathrm{~mm}$ above the NAc core $(2.20 \mathrm{~mm}$ anterior, $1.50 \mathrm{~mm}$ lateral to bregma, $6.40 \mathrm{~mm}$ ventral to skull surface). For intra-NAc shell infusions, bilateral guide cannulas are implanted $0.60 \mathrm{~mm}$ above the NAc shell $(2.70 \mathrm{~mm}$ anterior, $1.35 \mathrm{~mm}$ lateral to bregma, $6.00 \mathrm{~mm}$ ventral to skull surface). Placements of guide cannulas were chosen according to standard coordinates (Paxinos and Watson, 1998). Note that NAc shell placement was targeted to the anterior-most portion of NAc. While there is disagreement about the classification of this region of NAc, reports suggest that the medial anterior portion of NAc is anatomically consistent with shell (Zahm and Heimer, 1993; Jongen-Rêlo et al., 1994; Riedel et al., 2002). This region of NAc shell was chosen to minimize diffusion of infusate into adjacent NAc core. An obdurator was inserted into each guide cannula to prevent blockage before the cue-induced cocaine-seeking test. Following surgery, animals from both Experiment 1 and 2 were closely monitored for 1 week, during which the catheters were flushed twice daily with heparinized physiological saline ( $30 \mathrm{U} / \mathrm{ml}$ heparin). To assess catheter patency during the period of cocaine self-administration, $0.1 \mathrm{ml}$ of brevital (1\%) was injected as necessary. Loss of muscle tone within $5 \mathrm{~s}$ after injection indicated a patent catheter.

Cocaine and food self-administration. Seven days following surgery, all rats were food restricted to reduce their weight to $\sim 85 \%$ of their ad libitum feed weight. Rats were given daily allotments of food $(\sim 12-20 \mathrm{~g})$ to reduce and subsequently maintain their target weight; restricted $85 \%$ weight levels were adjusted weekly to account for normal growth as per Harlan growth curves. Following 1 week of food restriction, rats were trained to press the active lever for food (rodent food pellet, $45 \mathrm{mg} / \mathrm{pellet}$, formula A/I) on a fixed-ratio 1 (FR1) schedule of reinforcement. The number of inactive lever presses was $<5 \%$ of that of active lever presses throughout the entire study. After food responding stabilized, rats began extended or limited cocaine-access self-administration on the following day; note that while food self-administration pretraining for cocaine self-administration groups could potentially confound cocaine responding, this is a well established method in acclimating rats to operant responding for cocaine (Ahmed and Koob, 1998; Baker et al., 2003; BenShahar et al., 2008; Sari et al., 2009; Fischer-Smith et al., 2012). Sessions were conducted once per day for 11 consecutive days as in our previous study (Fischer-Smith et al., 2012). Pressing the active lever was reinforced by an infusion of cocaine $(0.75 \mathrm{mg} / \mathrm{kg}$ cocaine in a volume of $0.1 \mathrm{ml}$ over $2.8 \mathrm{~s}$ ) on a FR1 schedule. Each cocaine infusion was paired with a cue (light and tone) that lasted $4 \mathrm{~s}$ and was followed by a $36 \mathrm{~s}$ time-out signaled by illumination of the house light. For Experiment 1 rats, each session lasted 2 or $6 \mathrm{~h}$ or until animals received a maximum of 60 (limited) or 180 (extended) infusions of cocaine. Thus, maximum amounts of cocaine per limited and extended self-administration session were 15.0 and $45.0 \mathrm{mg}$, respectively. Food groups with identical handling and food training were run on either limited or extended schedules, but were reinforced with food pellets. For Experiment 2 rats, all cocaine and food groups were run on the described $6 \mathrm{~h}$ extended cocaine or food-access self-administration program, respectively. In all Experiment 1 and 2 rats, withdrawal began on the following day.

Withdrawal and drug treatment. Rats from Experiment 1 were assigned to one of two withdrawal groups as previously described (Fischer-Smith et al., 2012): short withdrawal ( $2 \mathrm{~d}$ of withdrawal) or long withdrawal (45 $\mathrm{d}$ of withdrawal). All withdrawal took place in the home environment. Short-withdrawal groups received (i.p.) $200 \mathrm{mg} / \mathrm{kg}$ ceftriaxone or salinetreatment vehicle (equal volume of $0.9 \%$ saline) shortly after each of the last $4 \mathrm{~d}$ of self-administration and during the single day of withdrawal. Long-withdrawal groups received (i.p.) $200 \mathrm{mg} / \mathrm{kg}$ ceftriaxone or salinetreatment vehicle on withdrawal days 40-44. For Experiment 2, all groups were placed on long withdrawal and received (i.p.) $200 \mathrm{mg} / \mathrm{kg}$ ceftriaxone or saline-treatment vehicle on withdrawal days $40-44$. All injections were administered at the same time for 5 consecutive days. It is well established that the dosing regimen of $200 \mathrm{mg} / \mathrm{kg}$ ceftriaxone for 5 consecutive days increases functional expression of GLT1 (Rothstein et al., 2005; Chu et al., 2007; Lipski et al., 2007; Mineur et al., 2007; Ouyang et al., 2007; Rawls et al., 2007). The lengths of withdrawal periods were based on prior literature showing cocaine-induced behavioral incubation effects or lack thereof for short-withdrawal groups (Conrad et al., 2008); the $2 \mathrm{~d}$ withdrawal period instead of the previously reported $1 \mathrm{~d}$ period was chosen to ensure a $24 \mathrm{~h}$ period from the last ceftriaxone or vehicle injection to the cue-induced cocaine-seeking test. Also, we previously reported that treatment with ceftriaxone during a $5 \mathrm{~d}$ extinction period from cocaine self-administration attenuated cue-induced cocaine reinstatement (Sari et al., 2009); here we wanted to test for cue-induced cocaine seeking following a shorter period away from the drug.

Cue-induced cocaine-seeking and food-seeking tests. The cue-induced cocaine-seeking and food-seeking test began $24 \mathrm{~h}$ following the last treatment for all cocaine-seeking and food-seeking groups, respectively. In Experiment 1, rats were presented with the cue for $4 \mathrm{~s}$ followed by a $36 \mathrm{~s}$ time-out as in the cocaine self-administration sessions. Responding was reinforced by the cue alone, contingent on a FR1 schedule in which the first presentation of the cue occurred either contingently in response to the first lever press or noncontingently if no lever press occurred within the initial $60 \mathrm{~s}$ of the test session. Each cue-induced test lasted $60 \mathrm{~min}$. Note that cue-induced cocaine seeking was assessed in extinction test sessions in which lever presses led to contingent cue presentations but 
not cocaine. In Experiment 2, 10 min before the cue-induced cocaineseeking test, rats previously trained on cocaine self-administration and treated with ceftriaxone were bilaterally infused with $500 \mu \mathrm{M}$ DHK (Fletcher and Johnston, 1991) into core or shell, $250 \mu \mathrm{M}$ DL-TBOA (Jabaudon et al., 2000) into core, or saline-infusion vehicle (equal volume of $0.9 \%$ saline) into core or shell. Because we previously found NAc GLT1 to be downregulated in extended-access long-withdrawal rats (Fischer-Smith et al., 2012), GLT1 blockers were not infused into salinetreated cocaine groups to avoid excitotoxic-related events. Thus, rats treated with saline-treatment vehicle were bilaterally infused into core or shell with saline-infusion vehicle only. Rats previously trained on food self-administration and treated with ceftriaxone or saline-treatment vehicle received $500 \mu \mathrm{M}$ DHK in core or shell, $250 \mu \mathrm{M}$ DL-TBOA in core, or saline-infusion vehicle in core or shell. All infusions occurred at a flow rate of $0.05 \mu \mathrm{l} / \mathrm{min}$ (Myers, 1966; Kupchik et al., 2012). Following the 10 min infusion period, the cue-induced cocaine-seeking or food-seeking test was run as above.

Western blots. For Experiment 1, rats were killed by rapid decapitation and brains were removed immediately following the cue-induced cocaine-seeking or food-seeking test. NAc core and shell were extracted and processed for immunoblotting as previously described (FischerSmith et al., 2012) using guinea pig anti-GLT1 and mouse antiglyceraldehyde-3-phosphate dehydrogenase (GAPDH; loading control) primary antibodies with corresponding horseradish peroxidase (HRP)tagged secondary antibodies. Following secondary antibody incubation, membranes were incubated with IRDye $800 \mathrm{CW}$ rabbit anti-HRP at 1:1000 dilution in Chemi-IR diluent (LI-COR Biosciences) for $1 \mathrm{~h}$ at $25^{\circ} \mathrm{C}$. After incubation, membranes were imaged on the Odyssey Infrared Imaging System (LI-COR Biosciences). Digitized images of immunoreactive proteins were quantified using an image analysis system. A ratio of the GLT1/GAPDH optical densities was determined for each sample and compared with the ratio of the optical densities of GLT1/ GAPDH of saline-treated food controls (food control ratio of the optical densities of GLT1/GAPDH was set to $100 \%$ ). Protein extractions and Western blots were performed in parallel for each group, including one food control per gel for comparison. Each gel included both core and shell samples from individual experimental animals.

Histological analysis. For Experiment 2, rats were perfused and brains removed for subsequent cannula placement verification immediately following the cue-induced cocaine-seeking or food-seeking test. Rats were deeply anesthetized with ketamine $(160 \mathrm{mg} / \mathrm{kg})$ and xylazine $(20 \mathrm{mg} / \mathrm{kg})$ followed by intracardial perfusion with $10 \%$ formalin and $1.5 \%$ potassium ferrocyanide. Coronal slices (50 $\mu \mathrm{m}$ thick) were compared with the stereotaxic atlas (Paxinos and Watson, 1998); only data from cannulas clearly placed within core and shell were included in subsequent analyses.

Drugs. Cocaine hydrochloride was provided by the National Institute on Drug Abuse. Ceftriaxone was purchased from Sigma-Aldrich. Both drugs were dissolved in physiological $(0.9 \%)$ saline solution.

Statistical analyses. One-way, two-way, and three-way ANOVAs were used to analyze behavioral and Western blot data. Multiple comparisons between and within groups were made with Tukey's HSD (honestly significant difference) and Bonferroni-pairwise comparisons tests. Correlations between both core and shell GLT1 expression and cueinduced cocaine-seeking behavior were determined with Pearson's correlation coefficients; Fisher's $Z$-transformation was used to compare between correlations. All statistical tests were based on $p<0.05$ level of significance.

\section{Results}

Extended cocaine-access rats display an escalation in cocaine consumption; limited cocaine-access rats exhibit stable responding

As revealed by two-way ANOVA, there were significant differences in cocaine consumption between limited-access and extendedaccess rats across self-administration days $\left(F_{(2,1207)}=270.78, p<\right.$ $0.0001)$. These results are summarized in Figure 1. Bonferroni's multiple-comparison test indicated an escalation in cocaine consumption only in extended cocaine-access rats on days 7-11 com-

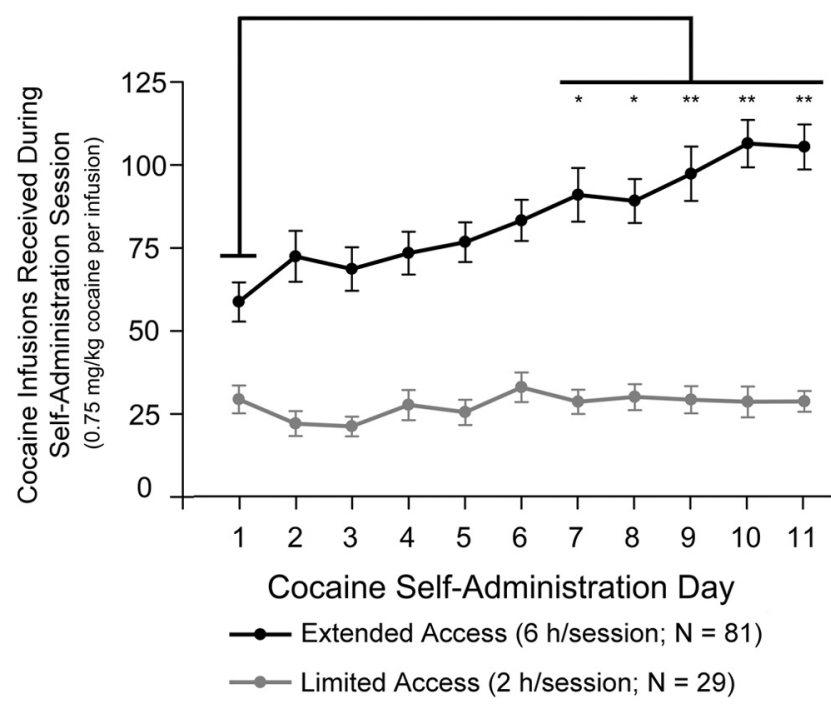

Figure 1. Cocaine infusions received for all limited-access and extended-access groups during each day of cocaine self-administration. No significant differences occurred in the number of daily infusions received either between limited-access groups or between extended-access groups. The number of cocaine infusions received by all extended-access rats during selfadministration sessions 7-11 was significantly higher than that for session $1\left(^{*} p<0.05\right.$; ${ }^{* *} p<0.0001$ ); no significant differences were reported between self-administration sessions in limited-access rats. Error bars indicate SEM. N, number of animals for each group.

pared with day 1 . No differences in responding occurred between limited cocaine-access groups or between extended cocaine-access groups. No differences in responding occurred within or between food self-administration groups. None of the groups differed in body weight; all rats were within $15 \mathrm{~g}$ of each other.

\section{Experiment 1}

Ceftriaxone attenuates cue-induced cocaine-seeking behavior in long-withdrawal limited and extended cocaine-access groups Cocaine-seeking groups. Three-way ANOVA revealed a significant difference in cue-induced cocaine seeking $\left(F_{(7,48)}=23.70 ; p<\right.$ 0.0001 ; access-withdrawal day-treatment interaction $F_{(1,55)}=$ 15.12, $p=0.0003$; Figure 2). Consistent with other reports (Grimm et al., 2001; Conrad et al., 2008), Tukey-Kramer's HSD test revealed significantly greater responding in saline-treated, limited cocaine-access long-withdrawal versus short-withdrawal groups, as well as in saline-treated, extended cocaine-access longwithdrawal versus short-withdrawal groups. Responding was significantly lower in ceftriaxone-treated versus saline-treated, limited cocaine-access long-withdrawal groups as well as in ceftriaxone-treated versus saline-treated, extended cocaine-access long-withdrawal groups. Saline-treated, extended cocaine-access longwithdrawal groups responded significantly more than similarly treated limited-access groups; conversely, ceftriaxone-treated, extended cocaine-access long-withdrawal groups responded significantly less than similarly treated limited-access groups. No differences occurred between saline-treated and ceftriaxonetreated, limited cocaine-access short-withdrawal and extended cocaine-access short-withdrawal groups.

Food-seeking groups. Three-way ANOVA revealed no differences in cue-induced food-seeking behavior between access, withdrawal, or treatment groups.

NAc core GLT1 expression is upregulated following ceftriaxone treatment in long-withdrawal limited and extended cocaine-access groups

NAc core and shell GLT1 expression in saline-treated, food-seeking groups. No significant differences were found in NAc core or shell 


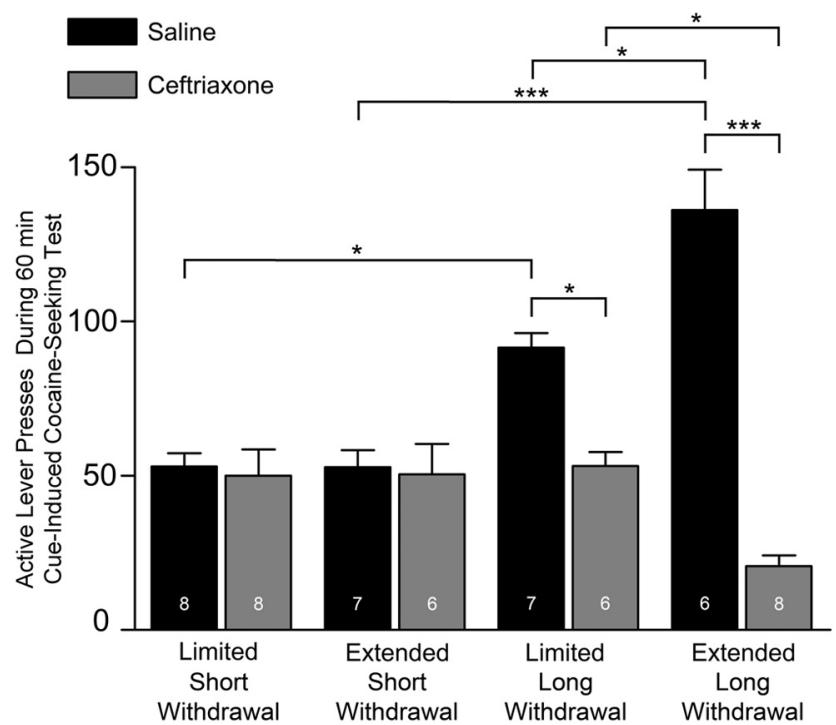

Figure 2. Effects of treatment with $200 \mathrm{mg} / \mathrm{kg}$ ceftriaxone or saline on cue-induced cocaineseeking behavior. Cue-induced cocaine seeking was significantly attenuated in ceftriaxonetreated long-withdrawal cocaine-seeking groups, with a greater effect in the extended-access group; no differences in responding occurred between saline-treated and ceftriaxone-treated short-withdrawal cocaine-seeking rats $\left({ }^{*} p<0.05 ;{ }^{* * *} p<0.0001\right)$. Error bars indicate SEM. The number of animals is listed for each group. Note that cue-induced cocaine seeking was assessed in extinction test sessions in which lever presses led to contingent cue presentations but not cocaine.

GLT1 expression between saline-treated, food-seeking rats in both access and withdrawal conditions; all experimental group expression levels were based on the average of all saline-treated food controls.

NAc core GLT1 expression in cocaine-seeking rats. Three-way ANOVA revealed significant differences in core GLT1 expression $\left(F_{(7,43)}=29.59 ; p<0.0001\right.$; access-withdrawal day-treatment interaction $F_{(1,50)}=16.08, p=0.0002$; Figure $3 A$ ). TukeyKramer's HSD test indicated core GLT1 expression to be significantly lower in the extended versus limited cocaine-access groups as well as in the long-withdrawal versus short-withdrawal cocaine-access groups. Core GLT1 expression was found to be significantly upregulated in ceftriaxone-treated, limited and extended cocaine-access long-withdrawal groups. No differences were detected between ceftriaxone-treated and saline-treated, limited or extended cocaine-access short-withdrawal groups. Core GLT1 expression upregulation was significantly greater in ceftriaxone-treated, extended cocaine-access long-withdrawal groups compared with similarly treated limited cocaine-access long-withdrawal groups.

NAc shell GLT1 expression in cocaine-seeking groups. Threeway ANOVA revealed significant differences in shell GLT1 expression $\left(F_{(7,43)}=7.38 ; p<0.0001\right.$; access effect $F_{(1,50)}=8.16$, $p=0.0066$; treatment effect $F_{(1,50)}=27.08, p<0.0001$; accesstreatment interaction $F_{(1,50)}=11.60, p=0.0014$; Figure $3 B$ ). Tukey-Kramer's HSD test indicated shell GLT1 expression to be significantly lower in the extended versus limited cocaine-access groups. No differences occurred between long-withdrawal and short-withdrawal cocaine-access groups. GLT1 expression in shell was found to be significantly upregulated in ceftriaxonetreated, extended cocaine-access groups; no changes occurred in limited cocaine-access groups.

NAc core and shell GLT1 expression in food-seeking groups. Three-way ANOVA revealed no changes in core or shell GLT1

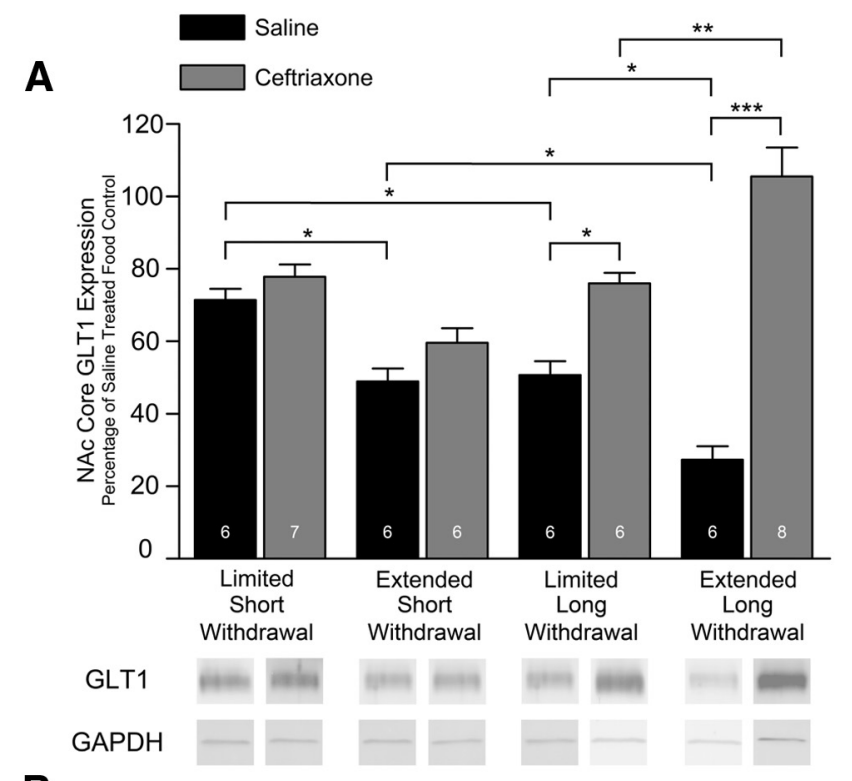

B

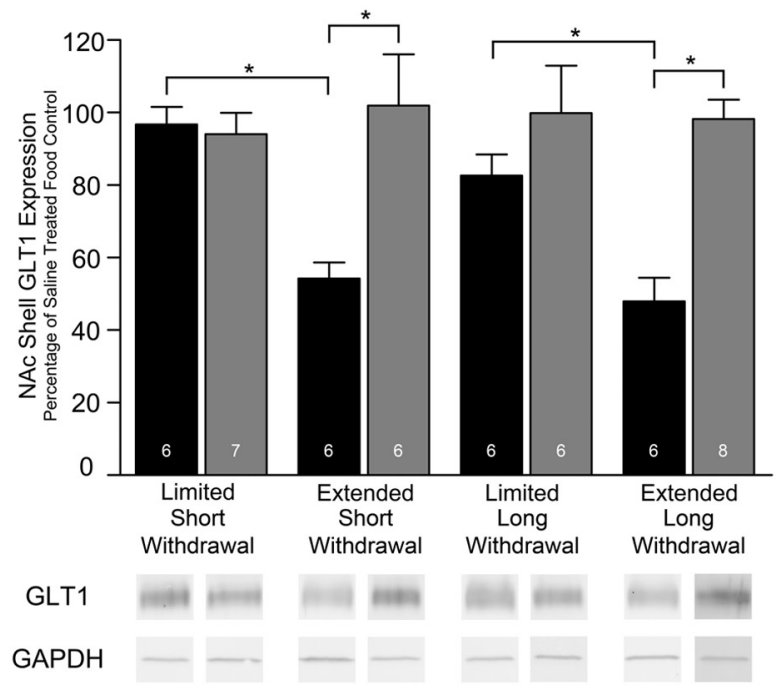

Figure 3. Effects of $200 \mathrm{mg} / \mathrm{kg}$ ceftriaxone and saline treatment on NAc GLT1 expression in cocaine-seeking rats. Each bar presents the experimental group GLT1/GAPDH to the average food control GLT1/GAPDH ratio notated as a percentage expression level. Each panel presents immunoblots for GLT1 and GAPDH, which was used as a control loading protein. $A$, In NAc core, no difference occurred between ceftriaxone-treated and saline-treated, limited or extended cocaine-access short-withdrawal groups, but a significant increase occurred in GLT1 expression in the long-withdrawal ceftriaxone-treated groups relative to saline, with a greater effect in the extended group $\left({ }^{*} p<0.05 ;{ }^{* *} p=0.0005 ;{ }^{* *} p<0.0001\right) . B$, In NAc shell, a significant increase in GLT1 expression occurred in both extended cocaine-access withdrawal conditions. Error bars indicate SEM. The number of animals is listed for each group.

expression between saline-treated and ceftriaxone-treated foodaccess groups.

Across all access, withdrawal, and treatment groups, NAc core, but not shell, GLT1 expression is inversely correlated with cue-induced cocaine-seeking behavior

Pearson's correlation coefficients revealed NAc core GLT1 expression across all access, withdrawal, and treatment groups to be significantly correlated with cue-induced cocaine-seeking behavior; no correlation was detected between NAc shell GLT1 expression and cue-induced cocaine-seeking behavior (Figure $4 A, B$ ). Across short withdrawal as well as both access and withdrawal groups, NAc core, but not shell, GLT1 expression was found to be 
A

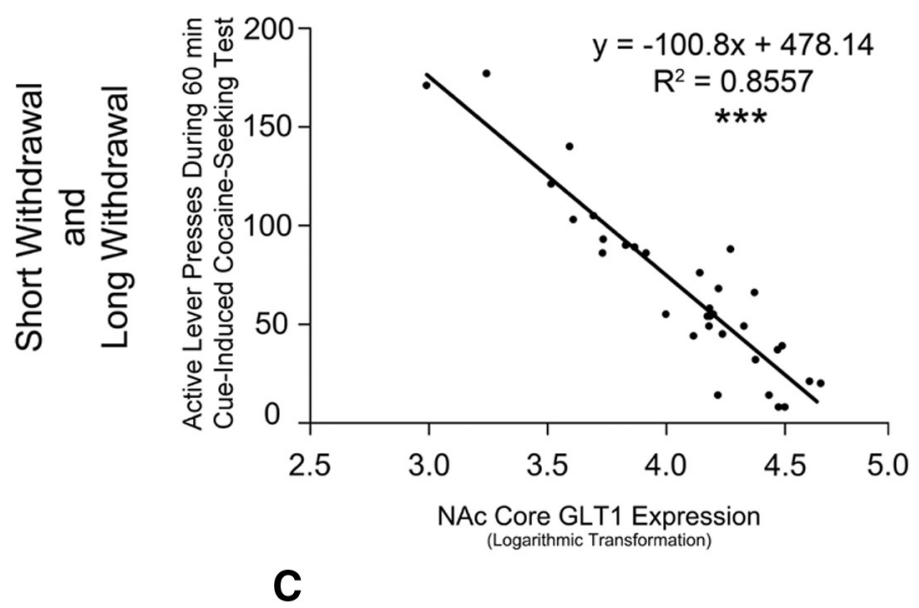

B

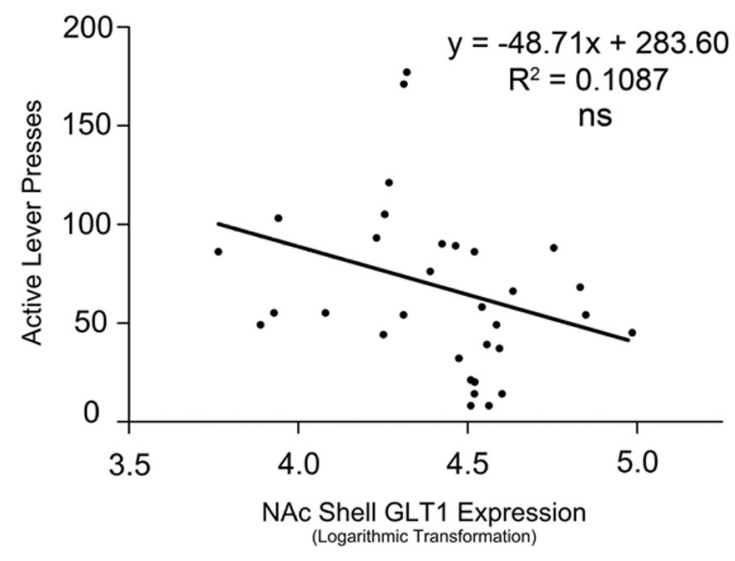

D
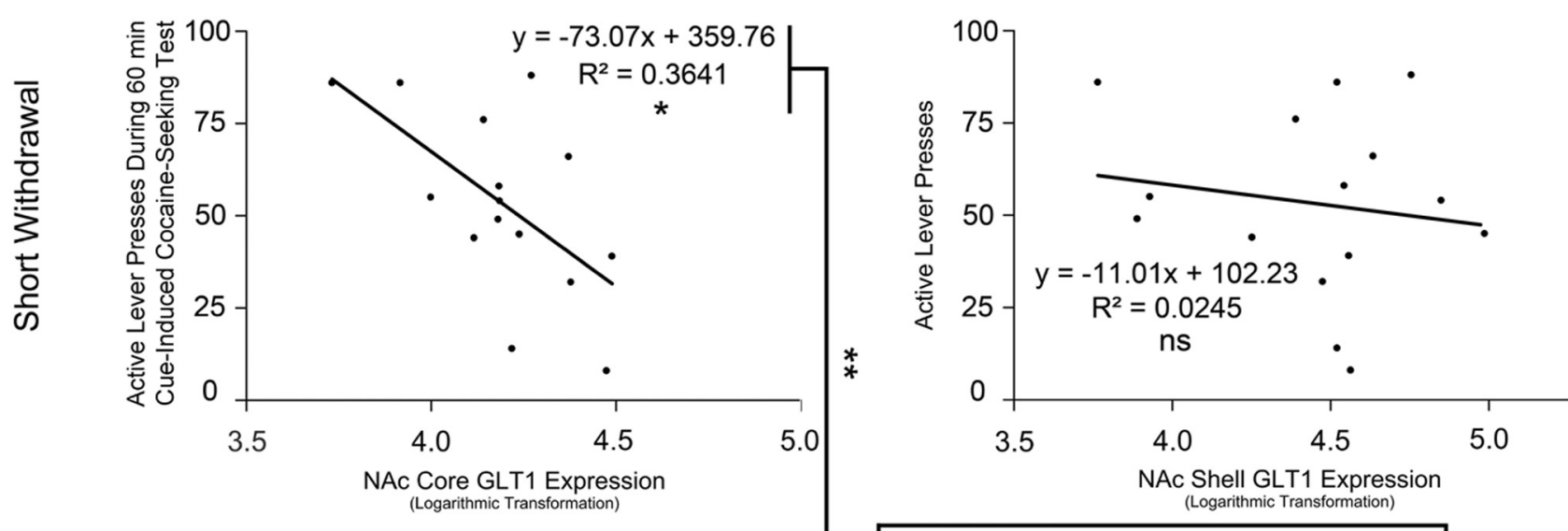

E
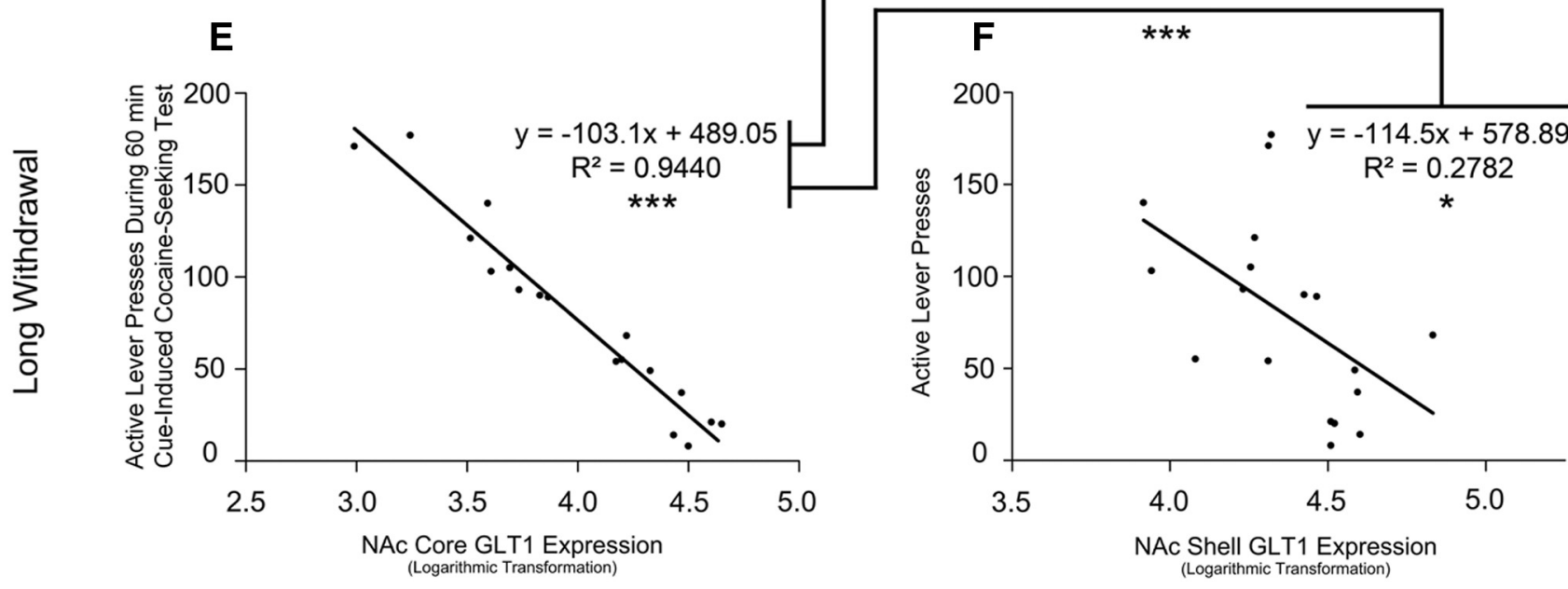

Figure 4. Log L $_{\mathrm{e}}$ transformation of GLT1 expression plotted against active lever presses during cue-induced cocaine relapse. $\boldsymbol{A}, \boldsymbol{B}$, Across all groups, NAc core $\left.{ }^{* * *} p<0.0001\right)$, but not shell ( $p=$ $0.0531)$, GLT1 expression was found to be correlated with cue-induced cocaine-seeking behavior. $\boldsymbol{C}, \boldsymbol{D}$, Across short-withdrawal groups, NAc core $\left({ }^{*} p=0.0172\right)$, but not shell $(p=0.5574)$, GLT1 expression was found to be correlated with cue-induced cocaine-seeking behavior. $\boldsymbol{E}, \boldsymbol{F}$, Across long-withdrawal groups, NAc core $\left({ }^{* * *} p<0.0001\right)$ and shell $\left({ }^{*} p=0.0245\right)$ GLT1 expression were found to be correlated with cue-induced cocaine-seeking behavior. The long-withdrawal NAc core group correlation $(\boldsymbol{E})$ was found to be significantly greater than both the long-withdrawal NAc shell group $\left(\boldsymbol{F} ; z=4.249,{ }^{* * *} p<0.0001\right)$ and the short-withdrawal NAc core group $\left(\boldsymbol{C} ; z=3.717,{ }^{* *} p=0.0002\right)$ correlations.

correlated with cue-induced cocaine-seeking behavior (Figure $4 C, D)$; across long withdrawal as well as both access and withdrawal groups, NAc core and shell GLT1 expression were found to be correlated with cue-induced cocaine-seeking behavior (Figure $4 E, F)$. Fisher's $Z$-transformation indicated the longwithdrawal NAc core group correlation to be significantly greater than both the long-withdrawal NAc shell group correlation and the short-withdrawal NAc core group correlation.

\section{Experiment 2}

NAc core GLT1 blockade reverses the ceftriaxone-mediated attenuation of cue-induced cocaine seeking

One-way ANOVA revealed significant differences in cue-induced cocaine seeking between treatment groups $\left(F_{(3,29)}=11.44 ; p<\right.$ 0.0001; Figure 5A). Tukey-Kramer's HSD test revealed significantly greater responding in saline-treated and saline-infused cocaine-seeking rats compared with ceftriaxone-treated, saline- 

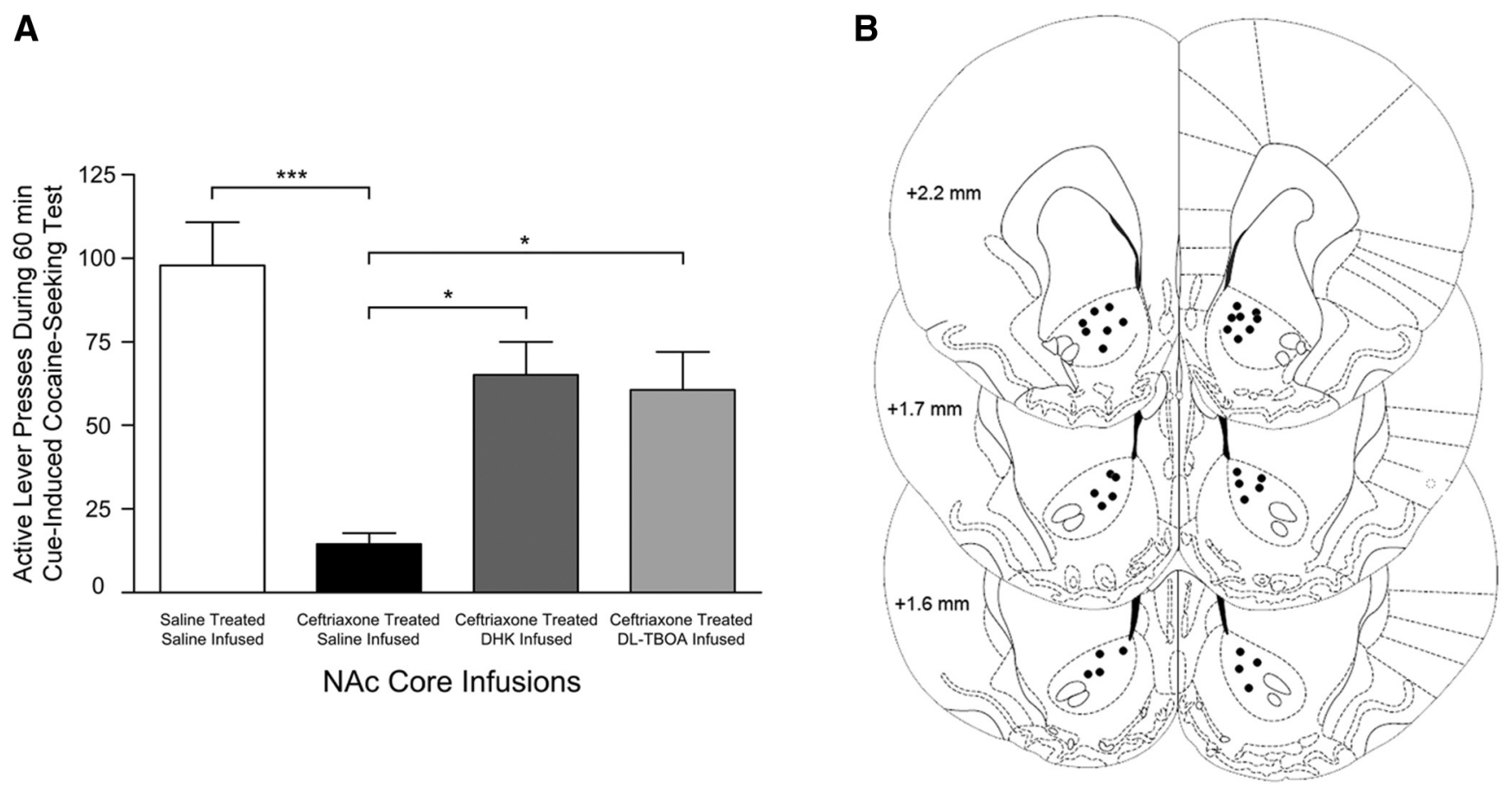

Figure 5. A, Effects of NAc core infusions of DHK and DL-TBOA on cue-induced cocaine seeking. This behavior was significantly attenuated in ceftriaxone-treated, saline-infused, cocaine-seeking groups compared with saline-treated, saline-infused, cocaine-seeking groups $\left({ }^{* * *} p<0.0001\right)$. Ceftriaxone-treated, DHK-infused and ceftriaxone-treated, DL-TBOA-infused rats responded significantly higher than ceftriaxone-treated, saline-infused rats (DHK, $\left.{ }^{*} p=0.0071 ; \mathrm{DL}-\mathrm{TBOA},{ }^{*} p=0.0246\right)$; no differences were detected when compared with saline-treated and saline-infused rats $(\mathrm{DHK}, p=0.1071 ; \mathrm{DL}-\mathrm{TBOA}, p=0.0798)$. Note that cue-induced cocaine seeking was assessed in extinction test sessions in which lever presses led to contingent cue presentations but not cocaine. $B$, Schematic representation of cannula tips in NAc core. Sections are presented $+2.2,+1.7$, and $+1.6 \mathrm{~mm}$ anterior to bregma.

infused rats. Responding was significantly higher in both ceftriaxone-treated, DHK-infused and ceftriaxone-treated, DLTBOA-infused rats compared with ceftriaxone-treated, salineinfused rats. Responding was not significantly higher in either ceftriaxone-treated, DHK-infused or the ceftriaxone-treated, DLTBOA-infused rats compared with saline-treated and salineinfused rats. Saline-treated, DHK-infused or DL-TBOA-infused, cocaine-access controls were not included to avoid excitotoxicrelated events since we previously found NAc core GLT1 expression to be significantly downregulated following long withdrawal from extended cocaine access (Fischer-Smith et al., 2012); but saline-treated, DHK-infused and DL-TBOA-infused food-access controls were included. One-way ANOVA revealed no differences in cue-induced food seeking between treatment groups. Figure $5 B$ indicates locations of the infusion sites within NAc core.

NAc shell GLT1 blockade has no effect on the ceftriaxonemediated attenuation of cue-induced cocaine-seeking behavior One-way ANOVA revealed significant differences in cue-induced cocaine seeking between treatment groups $\left(F_{(2,18)}=23.61 ; p<\right.$ 0.0001; Figure 6A). Tukey-Kramer's HSD test revealed significantly greater responding in saline-treated and saline-infused cocaine-seeking rats compared with ceftriaxone-treated, salineinfused and ceftriaxone-treated, DHK-infused rats. Responding was not significantly higher in ceftriaxone-treated, DHK-infused rats compared with ceftriaxone-treated, saline-infused rats. Saline-treated, DHK-infused or DL-TBOA-infused, cocaineaccess controls were not included to avoid possible excitotoxic effects as explained above. One-way ANOVA revealed no differences in cue-induced food seeking between treatment groups. Figure $6 B$ indicates locations of the infusion sites within NAc shell.

\section{Discussion}

We report that ceftriaxone treatment in limited and extended cocaine-access rats exposed to long withdrawal periods upregulates NAc core GLT1 expression and attenuates cue-induced cocaine-seeking behavior with a greater effect in extended-access rats. Cue-induced cocaine seeking was unaltered in either of the short-withdrawal cocaine-access conditions, suggesting a withdrawal period is critical to the therapeutic efficacy of ceftriaxone. Across all conditions, GLT1 expression in NAc core, but not shell, was significantly correlated with cue-induced cocaine-seeking behavior; long-withdrawal core groups had a significantly greater correlation compared with short-withdrawal core or longwithdrawal shell groups. Moreover, GLT1 blockade in core, but not shell, reversed the ceftriaxone-mediated attenuation of cueinduced cocaine seeking. Cue-induced food seeking, in contrast, was unaltered in ceftriaxone-treated or saline-treated rats following core or shell GLT1 blockade. Collectively, our results implicate core GLT1 in cocaine seeking after long withdrawal periods.

Alterations in core glutamate are coincident with cocaine reinstatement (Bell et al., 2000; Hotsenpiller et al., 2001; McFarland et al., 2003; Knackstedt et al., 2010). It is likely that attenuation of cue-induced cocaine-seeking behavior found here and cueinduced and cocaine-induced reinstatement found by others (Knackstedt et al., 2010) is due to NAc core GLT1 upregulation, which likely dampens the synaptic overflow of core glutamate release (Knackstedt et al., 2010). But a role for shell in cocaine reinstatement cannot be ruled out; in fact, AMPA receptor blockade in shell attenuates context-induced cocaine reinstatement (Fuchs et al., 2008; Xie et al., 2012). Additionally, inactivation of infralimbic cortex, which projects predominantly to shell (Sesack et al., 1989), inhibits cue-induced cocaine seeking following long withdrawal (Koya et al., 2009). Interestingly, however, shell inac- 


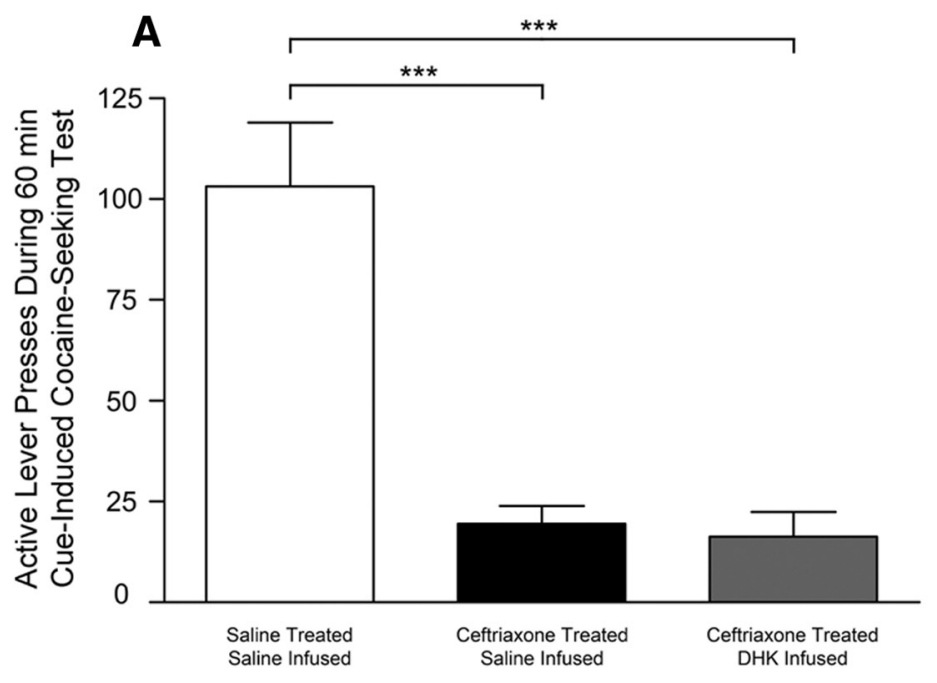

NAc Shell Infusions
B

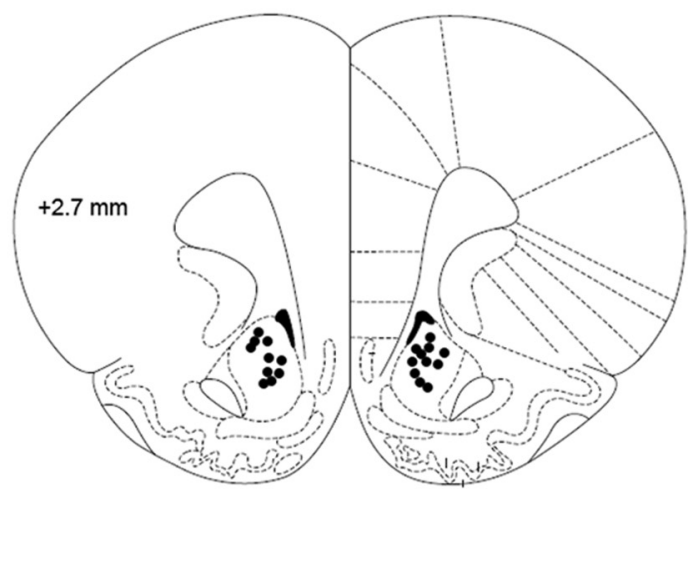

Figure 6. $\quad A$, Effects of NAc shell infusions of DHK on cue-induced cocaine-seeking behavior. Cue-induced cocaine seeking was significantly attenuated in the ceftriaxone-treated, saline-infused and ceftriaxone-treated, DHK-infused cocaine-seeking groups compared with the saline-treated and saline-infused cocaine-seeking groups $\left({ }^{* * *} p<0.0001\right.$ ). No differences were detected between ceftriaxone-treated, DHK-infused rats and the ceftriaxone-treated, saline-infused rats ( $p=0.9715$ ). Note that cue-induced cocaine seeking was assessed in extinction test sessions in which lever presses led to contingent cue presentations but not cocaine. $\boldsymbol{B}$, Illustration of cannula tips in NAc shell. Sections are presented $+2.7 \mathrm{~mm}$ anterior to bregma.

tivation has no effect on discrete cue-induced cocaine reinstatement (Fuchs et al., 2004).

Most of the research implicating NAc glutamate in cocaine reinstatement is based on the limited-access cocaine self-administration/extinction paradigm. However, the extended-access cocaine self-administration model captures key features underlying the transition into addiction, including consumption of large quantities of drug in a single setting and an escalation in drug consumption over time (Ahmed et al., 2000; Fischer-Smith et al., 2012). Although other factors could contribute to the escalation effect (Beckmann et al., 2012), it occurs in the cocaine but not food groups, suggesting the effect to be specific to drug seeking. In fact, extended cocaine access induces cellular and molecular changes in NAc, including increased dendritic branching (Ferrario et al., 2005), upregulation of mGluR 2/3 autoreceptors, and downregulation of mGluR 5 receptor expression (Hao et al., 2010), which are likely linked to addiction. Here, we found that NAc GLT1 expression was significantly lower in the salinetreated extended versus limited cocaine groups, but cue-induced cocaine seeking was similar between these groups, suggesting that the relationship between GLT1 and cue-induced cocaine seeking depends on a longer withdrawal period. In fact, long withdrawal periods (7-60 d) result in an incubation of cocaine craving as measured by increases in cue-induced cocaine seeking (Grimm et al., 2001; Conrad et al., 2008). In core, moreover, 45 d, but not $1 \mathrm{~d}$, of withdrawal from extended access increases calciumpermeable GluR2-lacking AMPA receptors (Conrad et al., 2008), and their blockade attenuates cue-induced cocaine relapse. Similarly, we found changes in core GLT1 expression as a function of increasing withdrawal (Fischer-Smith et al., 2012). We now report incubation in long-withdrawal groups, an effect attenuated following GLT1 upregulation in ceftriaxone-treated animals. Because core, but not shell, GLT1 blockade reversed the ceftriaxone-mediated effect in extended-access long-withdrawal animals, our results implicate core GLT1 in the incubation of cue-induced cocaine relapse. Although it was not directly assessed, this reversal likely extends to limited-access longwithdrawal groups given our data on GLT1 expression.
Ample evidence indicates that ceftriaxone, a $\beta$-lactam antibiotic known to cross the blood-brain barrier, increases GLT1 expression and function in healthy rodents (Rothstein et al., 2005; Miller et al., 2008; Knackstedt et al., 2010). The mechanism underlying the ceftriaxone-induced GLT1 upregulation has been shown to occur through activation of transcription factor nuclear factor $-\kappa \mathrm{B}(\mathrm{NF} \kappa \mathrm{B})$ (Lee et al., 2008). A previous report indicates chronic cocaine administration to increase expression of the p105 subunit of NF $\kappa$ B in NAc (Ang et al., 2001); it is thus conceivable for this pathway to be involved in the ceftriaxone-induced GLT1 upregulation. However, the fact that we find an NAc GLT1 downregulation following cocaine self-administration and withdrawal is not easily explained by Ang's report. It is plausible that the p105 subunit plays a role in regulation of GLT1 expression and its upregulation following chronic cocaine results in dysregulation of GLT1 expression. It is also important to note that the ceftriaxone-induced increase in GLT1 expression may not occur uniformly throughout the brain since, consistent with other evidence (Knackstedt et al., 2010), we found no change in NAc GLT1 expression in ceftriaxone-treated food controls. Because ceftriaxone treatment had no effect on NAc GLT1 expression in food controls but increased its expression in both longwithdrawal cocaine groups, the ceftriaxone-induced attenuation of cue-induced cocaine seeking may occur through restoration of GLT1 expression after a cocaine-induced decrease. Recent evidence, however, indicates a decrease in NAc extracellular glutamate levels in ceftriaxone-treated control rats (Rasmussen et al., 2011), and thus we cannot rule out a functional change in GLT1 in our ceftriaxone-treated groups.

Interestingly, the attenuation of cue-induced cocaine seeking by ceftriaxone was greater in the extended versus limited cocaine long-withdrawal groups. The greater increase in core GLT1 expression between the saline-treated and ceftriaxone-treated longwithdrawal groups may underlie the greater attenuation of cocaine seeking in the extended-access long-withdrawal group. These rats, moreover, are associated with greater downregulation of GLT1 expression. Thus, greater dysregulation of the pathways mediating GLT1 expression, which includes $\mathrm{NF} \kappa \mathrm{B}$ (Lee et al., 
2008), could be the underlying cause. Ceftriaxone's lack of effect on cue-induced cocaine-seeking behavior and core GLT1 expression in short-withdrawal groups suggests an interaction between cocaine self-administration and ceftriaxone that may prevent GLT1 upregulation. Thus, several days of withdrawal or extinction training are necessary for the ceftriaxone-mediated attenuation of cue-induced cocaine-seeking behavior. It is also important to note that GLT1 upregulation occurred in shell in extended-access short-withdrawal groups, which continued to relapse. Collectively, these findings suggest the attenuation of cue-induced cocaine-seeking behavior is mediated by GLT1 upregulation in NAc core.

DHK and DL-TBOA are effective inhibitors of GLT1 (Ferkany and Coyle, 1986; Fletcher and Johnston, 1991; Shimamoto et al., 1998; Jabaudon et al., 2000; Rasmussen et al., 2011). Concentrations for DHK and DL-TBOA for this report were chosen based on prior literature showing effective binding and blockade (Fletcher and Johnston, 1991; Jabaudon et al., 2000). It is unlikely that our local infusions acted outside our target sites given prior literature on brain diffusion dynamics indicating the chosen flow rate and volume to stay within similarly sized brain regions (Myers, 1966). Moreover, the clear difference in cocaine seeking between shell and core GLT1 blockade makes diffusion between shell and core unlikely.

Although DHK selectively blocks GLT1 over other glutamate transporters (Pines et al., 1992; Arriza et al., 1994), an action at glutamate receptors has been reported (Bridges et al., 1991; Maki et al., 1994), complicating interpretations based on DHK alone. In contrast, DL-TBOA has no discernible activity at glutamate receptors, but nonselectively blocks glutamate transporters (Shimamoto et al., 1998). Thus, because both GLT1 blockers reversed the ceftriaxone-induced decrease in cue-induced cocaine seeking, GLT1 blockade is the likely underlying mechanism. However, to avoid excitotoxic-related events, we did not infuse DHK or TBOA into saline-treated animals, because NAc GLT1 was found to be downregulated in rats following long withdrawal from extended cocaine access (Fischer-Smith et al., 2012). NAc GLT1 blockade had no effect on cue-induced seeking behavior in saline-treated food-access rats, indicating that GLT1 blockade alone does not potentiate operant responding for reward. It also is relevant that an effect of ceftriaxone on other transporters is unlikely given that expression of glutamate-aspartate transporter, EAAC1, and EAAT4 remain unaffected (Rothstein et al., 2005).

Interestingly, See et al. (2007) reported that transient inactivation of NAc core or shell by local infusion of GABA agonists had no effect on cue-induced cocaine relapse following $14 \mathrm{~d}$ of withdrawal from cocaine self-administration. These results are difficult to interpret, however, because transient inactivation of one brain region cannot rule out compensatory changes in other regions that may allow the behavior to persist. By manipulating GLT1 specifically, we can alter NAc output without activating such compensatory mechanisms (Giertler et al., 2004) to provide a clearer picture of the physiological role of NAc GLT1 in cueinduced cocaine relapse.

A role for NAc core in the extinction/reinstatement model of cocaine seeking is well established. We extend these findings by implicating core, but not shell, GLT1 in cue-induced cocaine seeking after withdrawal in the absence of extinction training. Additionally, the efficacy of ceftriaxone in suppressing the cocaine-seeking response requires an extended period of cocaine withdrawal. Thus, our results highlight the importance of core glutamate transmission in the development of drug relapse after withdrawal and point to GLT1 as a potential therapeutic target.

\section{References}

Ahmed SH (2012) The science of making drug-addicted animals. Neuroscience 211:107-125. CrossRef Medline

Ahmed SH, Koob GF (1998) Transition from moderate to excessive drug intake: change in hedonic set point. Science 282:298-300. CrossRef Medline

Ahmed SH, Walker JR, Koob GF (2000) Persistent increase in the motivation to take heroin in rats with a history of drug escalation. Neuropsychopharmacology 22:413-421. CrossRef Medline

Ang E, Chen J, Zagouras P, Magna H, Holland J, Schaeffer E, Nestler EJ (2001) Induction of nuclear factor-kB in nucleus accumbens by chronic cocaine administration. J Neurochem 79:221-224. CrossRef Medline

Arriza JL, Fairman WA, Wadiche JI, Murdoch GH, Kavanaugh MP, Amara SG (1994) Functional comparisons of three glutamate transporter subtypes cloned from human motor cortex. J Neurosci 14:5559-5569. Medline

Baker DA, McFarland K, Lake RW, Shen H, Tang XC, Toda S, Kalivas PW (2003) Neuroadaptations in cystine-glutamate exchange underlie cocaine relapse. Nat Neurosci 6:743-749. CrossRef Medline

Beckmann JS, Gipson CD, Marusich JA, Bardo MT (2012) Escalation of cocaine intake with extended access in rats: dysregulated addiction or regulated acquisition? Psychopharmacology 222:257-267. CrossRef Medline

Bell K, Duffy P, Kalivas PW (2000) Context-specific enhancement of glutamate transmission by cocaine. Neuropsychopharmacology 23:335-344. CrossRef Medline

Ben-Shahar O, Posthumus EJ, Waldroup SA, Ettenberg A (2008) Heightened drug-seeking motivation following extended daily access to selfadministered cocaine. Prog Neuropsychopharmacol Biol Psychiatry 32: 863-869. CrossRef Medline

Bridges RJ, Stanley MS, Anderson MW, Cotman CW, Chamberlin AR (1991) Conformationally defined neurotransmitter analogues. Selective inhibition of glutamate uptake by one pyrrolidine-2,4-dicarboxylate diastereomer. J Med Chem 34:717-725. CrossRef Medline

Capriles N, Rodaros D, Sorge RE, Stewart J (2003) A role for the prefrontal cortex in stress- and cocaine-induced reinstatement of cocaine seeking in rats. Psychopharmacology (Berl) 168:66-74. CrossRef Medline

Chu K, Lee ST, Sinn DI, Ko SY, Kim EH, Kim JM, Kim SJ, Park DK, Jung KH, Song EC, Lee SK, Kim M, Roh JK (2007) Pharmacological induction of ischemic tolerance by glutamate transporter-1 (EAAT2) upregulation. Stroke 38:177-182. Medline

Conrad KL, Tseng KY, Uejima JL, Reimers JM, Heng LJ, Shaham Y, Marinelli M, Wolf ME (2008) Formation of accumbens GluR2-lacking AMPA receptors mediates incubation of cocaine craving. Nature 454:118-121. CrossRef Medline

Danbolt NC (2001) Glutamate uptake. Prog Neurobiol 65:1-105. CrossRef Medline

Everitt BJ, Robbins TW (2005) Neural systems of reinforcement for drug addiction: from actions to habits to compulsion. Nat Neurosci 8:14811489. CrossRef Medline

Ferkany J, Coyle JT (1986) Heterogeneity of sodium-dependent excitatory amino acid uptake mechanisms in rat brain. J Neurosci Res 16:491-503. CrossRef Medline

Ferrario CR, Gorny G, Crombag HS, Li Y, Kolb B, Robinson TE (2005) Neural and behavioral plasticity associated with the transition from controlled to escalated cocaine use. Biol Psychiatry 58:751-759. CrossRef Medline

Fischer-Smith KD, Houston AC, Rebec GV. (2012) Differential effects of cocaine access and withdrawal on glutamate type 1 transporter expression in rat nucleus accumbens core and shell. Neuroscience 210:333-339. CrossRef Medline

Fletcher EJ, Johnston GA (1991) Regional heterogeneity of L-glutamate and L-aspartate high-affinity uptake systems in the rat CNS. J Neurochem 57:911-914. CrossRef Medline

Fuchs RA, Evans KA, Parker MC, See RE (2004) Differential involvement of the core and shell subregions of the nucleus accumbens in conditioned cue-induced reinstatement of cocaine seeking in rats. Psychopharmacology (Berl) 176:459-465. CrossRef Medline

Fuchs RA, Ramirez DR, Bell GH (2008) Nucleus accumbens shell and core 
involvement in drug context-induced reinstatement of cocaine seeking in rats. Psychopharmacology (Berl) 200:545-556. CrossRef Medline

Giertler C, Bohn I, Hauber W (2004) Transient inactivation of the rat nucleus accumbens does not impair guidance of instrumental behaviour by stimuli predicting reward magnitude. Behav Pharmacol 15:55-63. CrossRef Medline

Grimm JW, Hope BT, Wise RA, Shaham Y (2001) Neuroadaptation. Incubation of cocaine craving after withdrawal. Nature 412:141-142. CrossRef Medline

Hao Y, Martin-Fardon R, Weiss F (2010) Behavioral and functional evidence of metabotropic glutamate receptor $2 / 3$ and metabotropic glutamate receptor 5 dysregulation in cocaine-escalated rats: factor in the transition to dependence. Biol Psychiatry 68:240-248. CrossRef Medline

Hotsenpiller G, Giorgetti M, Wolf ME (2001) Alterations in behaviour and glutamate transmission following presentation of stimuli previously associated with cocaine exposure. Eur J Neurosci 14:1843-1855. CrossRef Medline

Jabaudon D, Scanziani M, Gähwiler BH, Gerber U (2000) Acute decrease in net glutamate uptake during energy deprivation. Proc Natl Acad Sci U S A 97:5610-5615. CrossRef Medline

Jongen-Rêlo AL, Voorn P, Groenewegen HJ (1994) Immunohistochemical characterization of the shell and core territories of the nucleus accumbens in the rat. Eur J Neurosci 6:1255-1264. CrossRef Medline

Kalivas PW, Lalumiere RT, Knackstedt L, Shen H (2009) Glutamate transmission in addiction. Neuropharmacology 56 [Suppl 1]:169-173. CrossRef Medline

Knackstedt LA, Melendez RI, Kalivas PW (2010) Ceftriaxone restores glutamate homeostasis and prevents relapse to cocaine seeking. Biol Psychiatry 67:81-84. CrossRef Medline

Koya E, Uejima JL, Wihbey KA, Bossert JM, Hope BT, Shaham Y (2009) Role of ventral medial prefrontal cortex in incubation of cocaine craving. Neuropharmacology 56 [Suppl 1]:177-185. CrossRef Medline

Kupchik YM, Moussawi K, Tang XC, Wang X, Kalivas BC, Kolokithas R, Ogburn KB, Kalivas PW (2012) The effect of N-acetylcysteine in the nucleus accumbens on neurotransmission and relapse to cocaine. Biol Psychiatry 71:978-986. CrossRef Medline

Lee SG, Su ZZ, Emdad L, Gupta P, Sarkar D, Borjabad A, Volsky DJ, Fisher PB (2008) Mechanism of ceftriaxone induction of excitatory amino acid transporter-2 expression and glutamate uptake in primary human astrocytes. J Biol Chem 283:13116-13123. CrossRef Medline

Lipski J, Wan CK, Bai JZ, Pi R, Li D, Donnelly D (2007) Neuroprotective potential of ceftriaxone in in vitro models of stroke. Neuroscience 146: 617-629. CrossRef Medline

Lu L, Grimm JW, Hope BT, Shaham Y (2004) Incubation of cocaine craving after withdrawal: a review of preclinical data. Neuropharmacology 47 [Suppl 1]:214-226. Medline

Lüscher C, Malenka RC (2011) Drug-evoked synaptic plasticity in addiction: from molecular changes to circuit remodeling. Neuron 69:650-663. CrossRef Medline

Maki R, Robinson MB, Dichter MA (1994) The glutamate uptake inhibitor L-trans-pyrrolidine-2,4-dicarboxylate depresses excitatory synaptic transmission via a presynaptic mechanism in cultured hippocampal neurons. J Neurosci 14:6754-6762. Medline

McFarland K, Kalivas PW (2001) The circuitry mediating cocaine-induced reinstatement of drug-seeking behavior. J Neurosci 21:8655-8663. Medline

McFarland K, Lapish CC, Kalivas PW (2003) Prefrontal glutamate release into the core of the nucleus accumbens mediates cocaine-induced reinstatement of drug-seeking behavior. J Neurosci 23:3531-3537. Medline

Miller BR, Dorner JL, Shou M, Sari Y, Barton SJ, Sengelaub DR, Kennedy RT, Rebec GV (2008) Up-regulation of GLT1 expression increases glutamate uptake and attenuates the Huntington's disease phenotype in the R6/2 mouse. Neuroscience 153:329-337. CrossRef Medline

Mineur YS, Picciotto MR, Sanacora G (2007) Antidepressant-like effects of ceftriaxone in male C57BL/6J mice. Biol Psychiatry 61:250-252. CrossRef Medline
Myers R (1966) Injection of solutions into cerebral tissue: relation between volume and diffusion. Physiol Behav 1:171-174. CrossRef

Ouyang YB, Voloboueva LA, Xu LJ, Giffard RG (2007) Selective dysfunction of hippocampal CA1 astrocytes contributes to delayed neuronal damage after transient forebrain ischemia. J Neurosci 27:4253-4260. CrossRef Medline

Paxinos G, Watson C. (1998) The rat brain in stereotaxic coordinates, 4th edition. New York: Academic.

Pines G, Danbolt NC, Bjørås M, Zhang Y, Bendahan A, Eide L, Koepsell H, Storm-Mathisen J, Seeberg E, Kanner BI (1992) Cloning and expression of a rat brain L-glutamate transporter. Nature 360:464-467. CrossRef Medline

Rasmussen BA, Baron DA, Kim JK, Unterwald EM, Rawls SM (2011) betaLactam antibiotic produces a sustained reduction in extracellular glutamate in the nucleus accumbens of rats. Amino Acids 40:761-764. CrossRef Medline

Rawls SM, Tallarida R, Robinson W, Amin M (2007) The beta-lactam antibiotic, ceftriaxone, attenuates morphine-evoked hyperthermia in rats. Br J Pharmacol 151:1095-1102. Medline

Riedel A, Härtig W, Seeger G, Gärtner U, Brauer K, Arendt T (2002) Principles of rat subcortical forebrain organization: a study using histological techniques and multiple fluorescence labeling. J Chem Neuroanat 23:75104. CrossRef Medline

Rothstein JD, Patel S, Regan MR, Haenggeli C, Huang YH, Bergles DE, Jin L, Dykes Hoberg M, Vidensky S, Chung DS, Toan SV, Bruijn LI, Su ZZ, Gupta P, Fisher PB (2005) Beta-lactam antibiotics offer neuroprotection by increasing glutamate transporter expression. Nature 433:73-77. CrossRef Medline

Sari Y, Smith KD, Ali PK, Rebec GV (2009) Upregulation of GLT1 attenuates cue-induced reinstatement of cocaine-seeking behavior in rats. J Neurosci 29:9239-9243. CrossRef Medline

See RE, Elliott JC, Feltenstein MW (2007) The role of dorsal vs ventral striatal pathways in cocaine-seeking behavior after prolonged abstinence in rats. Psychopharmacology (Berl) 194:321-331. CrossRef Medline

Sesack SR, Deutch AY, Roth RH, Bunney BS (1989) Topographical organization of the efferent projections of the medial prefrontal cortex in the rat: an anterograde tract-tracing study with Phaseolus vulgaris leucoagglutinin. J Comp Neurol 290:213-242. CrossRef Medline

Shimamoto K, Lebrun B, Yasuda-Kamatani Y, Sakaitani M, Shigeri Y, Yumoto N, Nakajima T (1998) DL-threo-beta-benzyloxyaspartate, a potent blocker of excitatory amino acid transporters. Mol Pharmacol 53: 195-201. Medline

Sondheimer I, Knackstedt LA (2011) Ceftriaxone prevents the induction of cocaine sensitization and produces enduring attenuation of cue- and cocaine-primed reinstatement of cocaine-seeking. Behav Brain Res 225: 252-258. CrossRef Medline

Sun W, Rebec GV (2003) Lidocaine inactivation of ventral subiculum attenuates cocaine-seeking behavior in rats. Neuroscience 23:10258-10264. Medline

Weiss F, Maldonado-Vlaar CS, Parsons LH, Kerr TM, Smith DL, Ben-Shahar O (2000) Control of cocaine-seeking behavior by drug-associated stimuli in rats: effects on recovery of extinguished operant-responding and extracellular dopamine levels in amygdala and nucleus accumbens. Proc Natl Acad Sci U S A 97:4321-4326. CrossRef Medline

Xie X, Lasseter HC, Ramirez DR, Ponds KL, Wells AM, Fuchs RA (2012) Subregion-specific role of glutamate receptors in the nucleus accumbens on drug context-induced reinstatement of cocaine-seeking behavior in rats. Addict Biol 17:287-299. CrossRef Medline

Zahm DS, Heimer L (1993) Specificity in the efferent projections of the nucleus accumbens in the rat: comparison of the rostral pole projection patterns with those of the core and shell. J Comp Neurol 327:220-232. CrossRef Medline

Zavala AR, Biswas S, Harlan RE, Neisewander JL (2007) Fos and glutamate AMPA receptor subunit coexpression associated with cue-elicited cocaine-seeking behavior in abstinent rats. Neuroscience 145:438-452. CrossRef Medline 